This document is the accepted manuscript version of the following article:
Dalaee, M. T., Gloor, L., Leinenbach, C., \& Wegener, K. (2020). Experimental and numerical study of the influence of

Dalaee, M. T., Gloor, L., Leinenbach, C., \& Wegener, K. (2020). Experimental and numerical study of the influence of
induction heating process on build rates Induction Heating-assisted laser Direct Metal Deposition (IH-DMD). Surface and

Coatings Technology, 384, 125275 (12 pp.).

https://doi.org/10.1016/j.surfcoat.2019.125275

This manuscript version is made available under the CC-BY-NC-ND 4.0 1icense http://creativecommons.org/1icenses/by-nc-nd/4.0/

\title{
Experimental and numerical study of the influence of induction heating process on build rates Induction Heating-assisted laser Direct Metal Deposition (IH-DMD)
}

\author{
Mohammad Taghi Dalaee ${ }^{\mathrm{a}, \mathrm{b}} *$, Lars Gloor ${ }^{\mathrm{b}}$, Christian Leinenbach ${ }^{\mathrm{c}}$, Konrad Wegener ${ }^{\mathrm{b}}$ \\ a inspire AG, ETH Zürich, Technoparkstrasse 1, 8005 Zürich, Switzerland \\ ${ }^{\mathrm{b}}$ Institute of Machine Tools \& Manufacturing (IWF), ETH Zürich, Leonhardstrasse 21, 8092 Zürich, Switzerland \\ c Empa, Swiss Federal Laboratories for Materials Science and Technology, Überlandstrasse 129, 8600 Dübendorf, Switzerland
}

\begin{abstract}
Direct Metal Deposition (DMD) technology proves advantageous in complex and precise component fabrications. Nevertheless, the typical productivity rate of the DMD process is not sufficient for fabricating large components. In this paper, the induction heating (IH) technique is presented to address this issue by assisting the DMD process by increasing the build-up rate.
\end{abstract}

For this purpose, the influences of different laser processing and induction heating factors are investigated to provide the information required for designing a suitable IH setup that is capable of integrating into the DMD process. Furthermore, a finite element simulation of IH is carried out using the COMSOL software package and the results are accordingly verified against experimental data. This helps design a Hybrid Induction DMD (IH-DMD) process by identifying a correlation between induction parameters and generated heating temperature on the component surface.

This paper presents the implementation setup of IH-DMD discusses its limitations. In a final setup, deposition of Inconel 625 powder material on the structure steel S235 with an IH-DMD process is examined to show the improvement gained. This includes different powder feed rates, scan speeds, and spot diameters. 
The results demonstrate the important role of the coil profile, magnetic flux concentrator, coupling gap, electric current in the coil, and coil shield to achieve a sufficient heating rate and stable IH-DMD coating process. The deposition rates and clad geometry are characterized. By employing IH-DMD, the coating deposition can be improved by a factor of three.

\section{Keywords}

Laser direct metal deposition, Hybrid induction heating laser cladding, High deposition rate additive manufacturing, Induction heating

\section{Introduction}

Direct Metal Deposition (DMD), where the powder is blown into the laser initiated melt pool, is widely used in coating and repair applications. This technology has been recently employed in Additive Manufacturing (AM) of complex components in industries. Heavy industry companies such as shipbuilding and turbomachinery manufacturing are good candidates to benefit from AM and thus seek to apply this technology in producing their components $[1,2]$. However, processing of large components with a typical DMD method is economically challenging due to the low deposition rate and consequently, high fabrication cycle times. Therefore, such applications require an efficient technology that provides a high quality level of DMD but also offers a high productivity level.

In a DMD operation, a focused laser beam melts the substrate and deposition material. However, laser energy is partially dissipated into the cold substrate due to heat conduction. This limits the thermal energy for the melt pool formation and thus restricts the deposition rate. An effective preheating technique which is able to heat up the substrate locally can compensate for the heat conduction losses of the melt pool in the cold layers underneath. Subsequently, higher temperatures in the melt pool allow the insertion of powder with a higher feed rate to form an accurate clad track with higher build-up rates. 
Electromagnetic Induction Heating (IH) is a well-suited heating process for this purpose since this method is a non-contact heating process, which can heat the components locally without contaminating the foreign matter as noted by Haimbaugh [3]. The technique is commonly used in different industrial applications, including heat treatment, hot forming, and joining processes. Inductors as a heating source can be coupled to a programmable machine (e.g., a robot or a $\mathrm{CNC}$ machine) to heat desired areas of the workpiece more accurately [4]. Heat treat cycles are relatively short, in the order of seconds and minutes, and can be monitored and controlled.

According to [5], IH is based on eddy current heating and hysteretic heating. Hysteretic heating refers to energy dissipation by the magnetic hysteresis losses in the ferromagnetic material during altering magnetic field. In eddy current heating, the electromagnetic field generated by the coil induces an eddy current on the workpiece, which consequently heats up the substrate according to the Joule effect. However, the heat effect attributed to hysteresis losses is approximately $6 \%-8 \%$ compared to the eddy current losses if the surface temperature of the heated workpiece is above Curie temperature.

The advantages mentioned motivated researchers to utilize this technique in coating applications to increase the productivity level and improve the quality of the coated layer. For instance, Zhou et al. analyzed a microstructure of a coating layer of a Ni-based WC composite alloy on preheated A3 mild steel substrate material by lateral laser induction hybrid rapid cladding [6]. They observed lower susceptibility of cracking in the coated layer compared to deposited layers without preheating. Jonnalagadda et al. performed induction assisted laser DMD setup using Fraunhofer COAXpowerline nozzle system, in which a quarter-turn induction coil coupled laterally to laser nozzle [7]. They deposited W2C-Ni Matrix on steel substrate and could increase the powder feed rate of $1.85 \mathrm{X}$ compared to the standard laser DMD process. A similar setup was presented by Nowotny et al. using a coaxial laser powder cladding head with an induction module to coat an Inconel 625 on large hydraulic cylinders [8]. 
They could increase the deposition rate by $50 \%$ from $5.1 \mathrm{~kg} / \mathrm{h}$ to $7.7 \mathrm{kh} / \mathrm{h}$ using a10 $\mathrm{kW}$ diode laser and an induction generator up to $50 \mathrm{~kW}$.

Recently, Wang et al. studied the influence of substrate temperature by induction heating on the coating deposition rate [9]. They observed the linear-like dependence between deposition rate and substrate temperature up to $750^{\circ} \mathrm{C}$ when coating $43 \mathrm{Ni}-50.8 \mathrm{Cr}-6.2 \mathrm{Si}$ powder material on an AISI 1045 carbon steel substrate. Improvement in the cladding efficiency and deposition rate above this temperature was not notable in their experiment.

In most investigations of hybrid, heating inductors coupled to the deposition head laterally, in which heating of a part is prior to coating a layer, referred to a "Preheating" setup. However, lateral installations restrict the deposition of layers to a unidirectional path, whereas the deposition path in AM application may consist of a bidirectional or a contouring movement of the deposition head. The principle concept of coaxially coupling IH with DMD to heat up the substrate simultaneously during the coating of layers has been patented by [10]. Nonetheless, a systematic investigation on a hybrid setup, proper selection of IH process parameters, and technical challenges in the implementation of the setup during the deposition of layers without bonding error is missing in the previous literature.

The present study addresses the challenges and limitations of an IH-DMD setup to give insight into the design and implementation of the hybrid system. The role of main IH parameters on the heating temperature is studied. For this purpose, a finite element simulation is carried out in COMSOL Multiphysics 5.3®, and results are verified against experiments. The developed model supports the selection of the hybrid IH-DMD setup by creating a correlation between process parameters and generated heat on the surface of components. Finally, hybrid setup is implemented and increases in the deposition rate in IH-DMD are analyzed considering sufficient metallurgical bonding between the clad layer and substrate in a single track. Laser 
processing parameters are optimized in connection with clad geometry in order to fabricate defect-free multiple layers.

\section{Theory and calculation}

\subsection{Coaxial IH-DMD setup and specification}

IH components that need to be installed in a DMD machine mainly include a power supply, a cooling unit, and an inductor. The components of an IH-DMD machine are schematically illustrated in Figure 1. There is typically an intermediate body between the inductor and the power supply, shown as "C-Box" in Figure 1. The role of this component is to connect the coil leads to the power supply mechanically and electrically. In addition, the cooling water also passes through this section to be delivered into the inductor-cooling pocket. A method of holding the inductor coaxially with the deposition nozzle and presenting it to the top of the part must be addressed during the initial design.

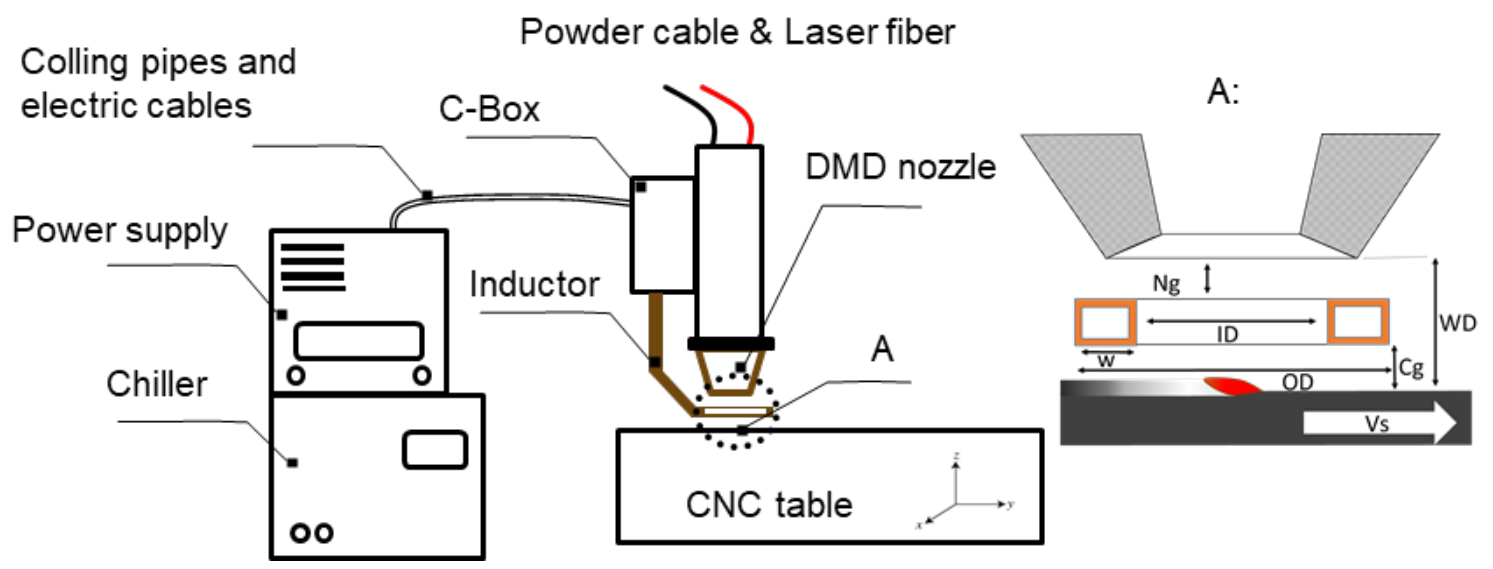

Figure 1: Schematic of IH-DMD components. Section A shows the coil profile of the inductor installed in the working distance (WD) of the DMD nozzle.

Thanks to the flexibility of cables, the connection movement of the $\mathrm{CNC}$ axis in $\mathrm{X}, \mathrm{Y}$ and $\mathrm{Z}$ directions is not limited, but tilting the DMD head or CNC table around $\mathrm{X}$ and $\mathrm{Y}$ may be restricted due to the risk of collision of the inductor with the substrate. The configuration of induction heat-treating coils strongly depends on the heating applications and part geometry as noted by Zinn and Semiatin [11]. An encircling coil shape is likely the most suitable form to be 
employed in an AM application since besides simultaneously preheating the surface near the melt pool as shown in Figure 2, the heating performance can be done in every moving direction of the DMD laser head. As elaborated upon in the work of [12], the induction coil design should fulfill the following requirements: meet heat treatment specifications in desired production rates, be robust enough to tolerate manufacturing variations, have electrical parameters that match the induction power supply and have a satisfactory lifetime and efficiency. These criteria play a significant role in the design and implementation of an IH-DMD setup, which is discussed in this section.

\subsubsection{Influence of DMD nozzle specification}

In the DMD process, a conical powder stream is formed at the nozzle exit, focused at a specific length from the tip of the nozzle, and then defocused. According to [13], the powder stream's focal point should be close to the level of the melt pool to obtain maximum powder catchment efficiency and clad quality. The powder focal length depends on nozzle types and their specifications, which determine the DMD operating distance called "Working Distance" (WD). The available space for the coupling of the inductor coaxially with the deposition head is limited to the WD. This factor, as well as the geometry of a nozzle, specifies the initial design of an inductor including the coil profile, the number of coil turns, and the Inner Diameter (ID). Accordingly, it influences the decision of modulating the coil and nozzle, including the "Nozzle gap" $(\mathrm{Ng})$ between the nozzle and the coil and the "Coupling gap" $(\mathrm{Cg})$ between the coil and the substrate (shown in Figure 1-A).

As shown in Figure 2, a smaller ID brings the intensity of the magnetic field closer to the melt pool zone, which leads to better heating efficiency. However, the ID of the coil should provide sufficient clearance for a homogeneous distribution of the powder particles, which is a key factor in the formation of a good quality clad. Furthermore, due to the close distance of the coil and powder outlet, the magnetic field generated by the coil may influence on the powder profile 
in case of the ferromagnetic powder materials. This concern has been investigated in the following chapter.

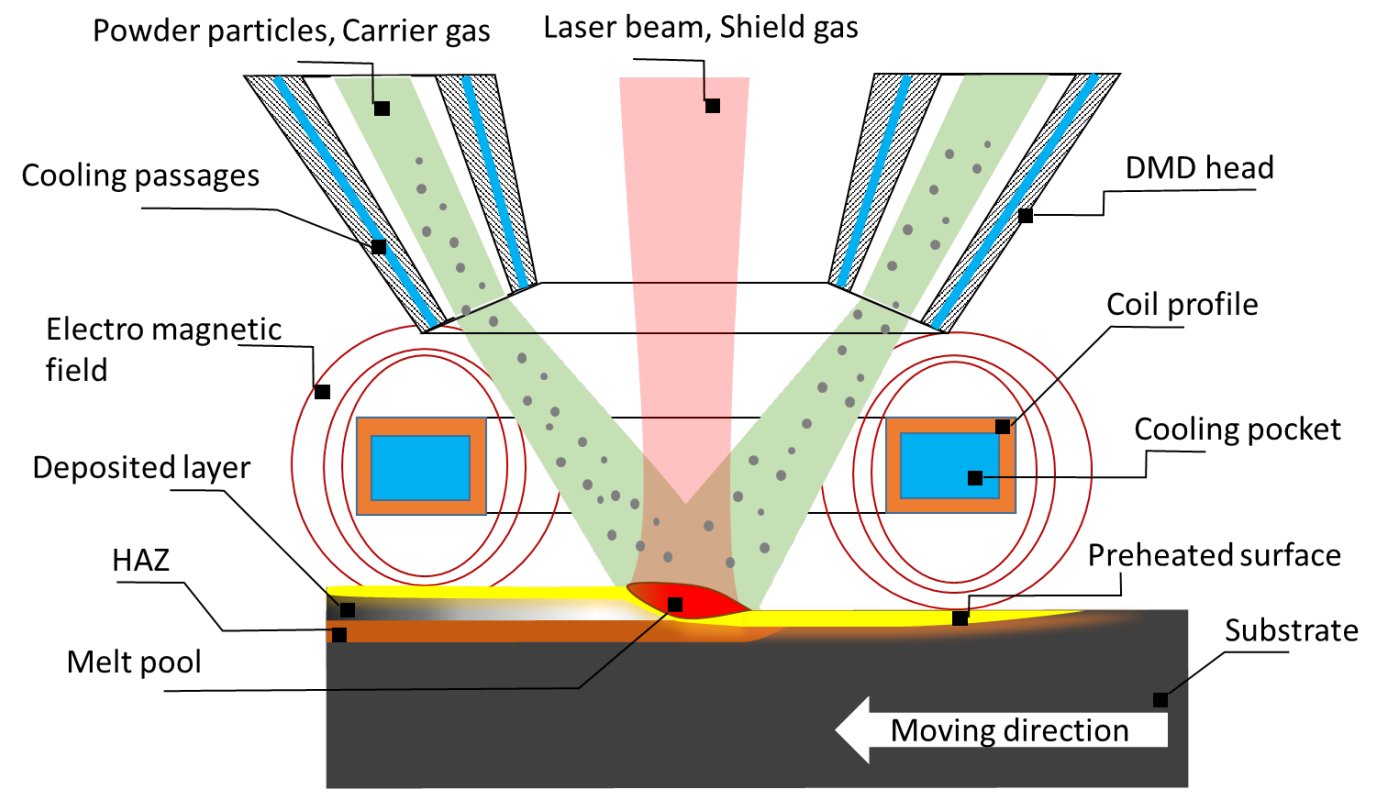

Figure 2: Schematic of a coaxial IH-DMD process.

It should be pointed out that the DMD nozzle and the inductor need to be cooled down during the process due to heat transfer from the hot surface of the part, and the eddy current losses in the nozzle and the inductor materials as described by [14-16]. Overheating of these elements can lead to cracking or deformation during the IH-DMD process.

\subsubsection{Influence of DMD and IH process parameters on the hybrid process}

In this chapter, the main IH parameters are addressed, which play a significant role in the induction power density and heat rate. The authors in [17] describe that the IH power density and heating times are influenced by the electric current flow in the coil $\left(I_{\text {coil }}\right)$, the frequency of induction heating (w), the width of heating face (W), the Magnetic Flux Controller (MFC) and the coupling gap $(\mathrm{Cg})$. MFC is a tool which is placed around the coil to alter the flow of the magnetic field. Detailed information about types and main categories of MFC materials has been described in [18]. These authors explained that magnetic fields and power density are much more concentrated under a coil when applying MFC, resulting in higher heating 
efficiency of the system. The heated area of the part can be extended wider with the bigger size of W. However, the current density under the heat face is inversely proportional to the width of the coil, which means higher induction power needs to be applied to maintain the power density. In this study, the coil width is selected according to the available WD and coil profile.

As suggested by [4], the frequency of IH needs to be chosen first since it has a strong influence on all electromagnetic phenomena including heating time, local distribution of power in part, and heating depth. They presented that the applied frequency is the most relevant parameter that directly affects the depth of heat generation, governed by the formula

$$
\delta=\sqrt{\frac{1}{\pi w \sigma \mu}}
$$

where $\delta$ is the skin depth, $\mathrm{w}$ is the frequency, and $\mu$ and $\sigma$ are the electrical conductivity and magnetic permeability of the workpiece, respectively. In IH-DMD, the required heating depth in the part is low since the melt pool depth, which corresponds to the desire IH area, is typically shallow on the surface, as shown in Figure 2. Therefore, a medium-range of induction frequencies above $50 \mathrm{kHz}$ can be examined. These are typically employed in induction surface heating applications (e.g., induction surface hardening [4]).

In addition to described IH parameters, the scan speed of the DMD process plays a vital role in the IH cycle because the position of the induction coil moves relative to the heated length of the part during deposition of layers, as shown in Figure 2. This means that the energy required to heat the preferred melt pool area to a certain temperature depends on not only the IH parameters and the material specification of the part, but also on the scan velocity. The typical DMD scan speed in a DMD process is relatively fast $(400-1600 \mathrm{~mm} / \mathrm{min}$ [13]), which determines the interaction time of induction power density in a given area of the substrate. Therefore, a rapid heating cycle in the range of milliseconds is necessary to heat up the substrate. 
The IH process is a complicated dynamic process composed of complex interacting phenomena involving electromagnetics, heat transfer, and materials science. To provide a successful design of the IH-DMD system, it is necessary to take into account the correlation between the described IH process parameters. For this purpose, a finite element simulation model of IH is studied in the next section to investigate the effect of $I_{\text {coil }}, \mathrm{w}, \mathrm{MFC}, \mathrm{Cg}$, and scan speed on the generated surface temperature.

\subsection{Finite Element Modeling of IH}

A model for IH was developed in COMSOL Multiphysics 5.3 ${ }^{\circledR}$ in the AC/DC module [19]. The equations governed in COMSOL, coupled to the coil and the substrate, are illustrated schematically in Figure 3, in which the eddy current heating, as well as the thermodynamic effects of conduction, convection, and radiation, were taken into account.

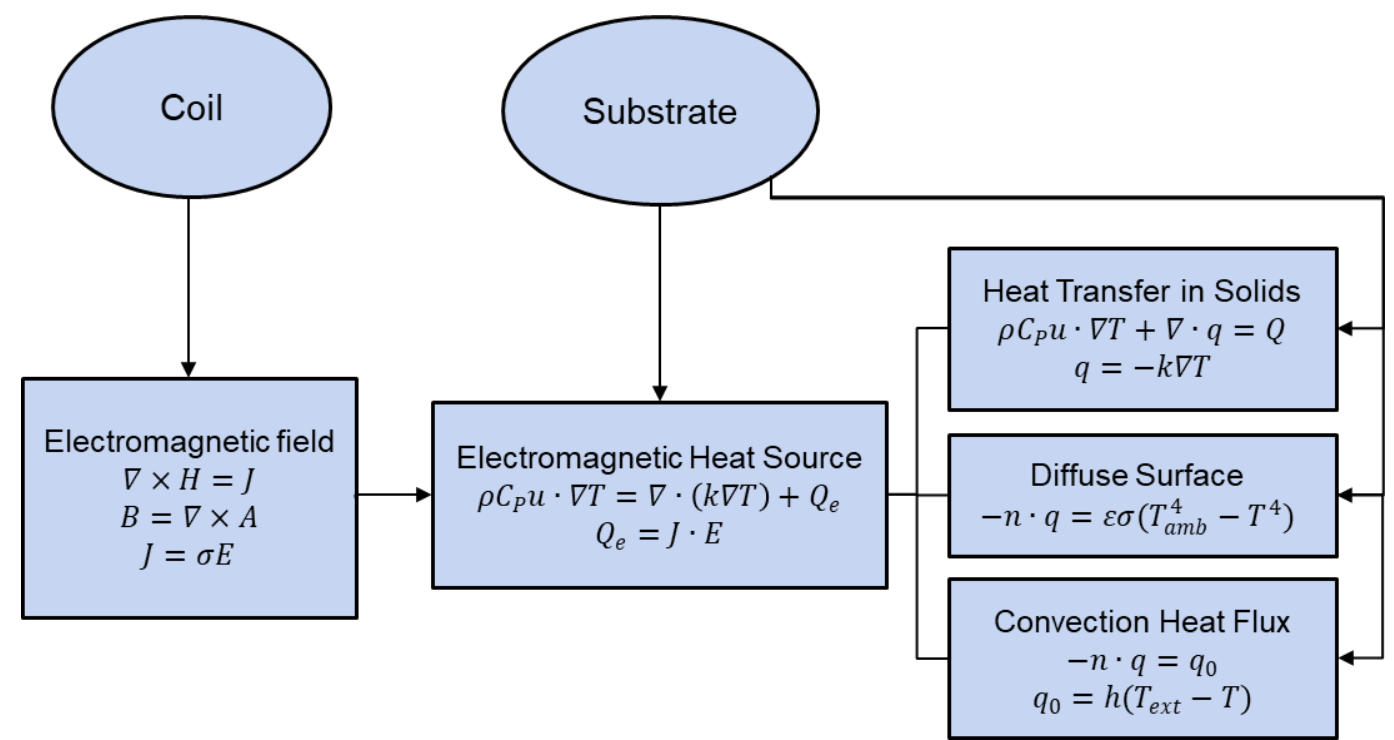

Figure 3: Mathematical equation and coupling in solving induction electromagnetic heating in COMSOL.

The equation to be solved in the model starts with Ampere's law and Maxwell's equations in the frequency domain [20]. Eddy current can be calculated by using the vector potential and is given by equation (2) 


$$
J=\sigma E=j w \sigma A+\nabla \times\left(\mu^{-1} B\right)
$$

with $J$ : the current density; E: electric field; $\sigma$ : the electrical conductivity; A: the vector potential; $B$ : the flux density; $w$ : the frequency; $\mu$ magnetic permeability of the material. Eddy current induced in the substrate material, which corresponds to a heat source is given by equation (3).

$$
Q_{e}=J \cdot E
$$

Heat transfer in the substrate was described by the law of heat conduction, which can be written as equation (4). Boundary conditions in heat transfer fields are the radiative and the conductive heat flux which can be represented by equation (5) and (6)

$$
\begin{gathered}
\rho C_{P} u \cdot \nabla T=\nabla \cdot(k \nabla T)+Q_{e} \\
-n \cdot q=\varepsilon \sigma\left(T_{a m b}^{4}-T^{4}\right) \\
q_{0}=h\left(T_{e x t}-T\right)
\end{gathered}
$$

with $Q_{e}$ : the heat produced by heat sources; $\rho$ : the density; $C_{P}$ : heat capacity at constant pressure and $k$ : thermal conductivity of the material; $u$ velocity field; $T$ : temperature field $q$ : heat flux and $q_{0}$ : general inward heat flux; and $\varepsilon$ : surface emissivity; $h$ : heat transfer coefficient; $T_{a m b}$ : ambient temperature; $T_{\text {ext }}$ : external temperature; $\sigma$ Stefan-Boltzmann constant; $n$ : refractive index. Electromagnetic and thermodynamic equations were coupled to the substrate via the electromagnetic power equation. The thermal isolation boundary condition is used at the bottom of the substrate.

A number of assumptions were used in defining the model. Firstly, it was assumed that the currents have a steady-state quality to simplify the mathematical model. With this assumption, electromagnetic field quantities in Maxwell's equations are harmonically oscillating functions with a single frequency as introduced by [5]. Finally, the properties of magnetic permeability and thermal conductivity, and electrical resistivity of the stainless steel material X3CrNiMo13- 
4 at $20^{\circ} \mathrm{C}$ were assigned to the model, listed in Table 1 to reduce the computational effort. During the heating cycle, variation can occur in the electrical resistivity, specific heat, thermal conductivity, and magnetic properties, which affects heat generation and temperature distribution on the substrate. The temperature-dependent data of these properties were not found in the literature for the examined material. However, by comparing the result of similar series of stainless steel $(410,430)$ reported by [21], it can be assumed that thermal conductivity is almost constant in the temperature range of $20^{\circ} \mathrm{C}-700^{\circ} \mathrm{C}$.

Table 1: material data of substrate X3CrNiMo13-4 [22]

\begin{tabular}{lcl}
\hline Quantity & Symbol & Value \\
\hline Electrical resistivity & $\Omega \times \mathrm{mm}^{2} / \mathrm{m}$ & 0.60 \\
Density & $\mathrm{kg} / \mathrm{m}^{3}$ & 7700 \\
Heat capacity & $J /(\mathrm{kg} \times \mathrm{K})$ & 430 \\
Thermal conductivity & $W /(\mathrm{m} \times \mathrm{K})$ & 25 \\
Relative magnetic & unitless & 60 \\
permeability & & \\
& & \\
\hline
\end{tabular}

Due to the symmetry of the problem half of the model was built with the multiform mesh distribution shown in Figure 4. A solution domain contains three zones including air, an inductor, and a substrate. The boundary condition of the air zone was magnetic insolation with initial vector potential $\mathrm{A}=0$. Meshes are denser on the surface of the substrate and in the coupling gap to achieve a proper calculation of electromagnetic phenomena and heat transfer. Simulations of the IH were performed with a single-turn coil, with and without MFC, and in both single-shot and scanning states. IH parameters were simulated concerning the key factors described in the previous section, including electric current flow in the coil $I_{\text {coil }}$, frequency of the magnetic field $\mathrm{w}$, and the coupling gap $\mathrm{Cg}$, with the variable values listed in Table 2 to evaluate heating temperature and distribution.

Two-point graphs were plotted to visualize the temperature as a function of time. Both points are positioned on the surface of the substrate, but the first is positioned in the center of the coil 
turn $(\mathrm{Tc})$ where the melt pool is formed in DMD process; the second under the edge of the coil face (Te). The default parameter setting and temperature measurement points are $\mathrm{Tc}$ at $\mathrm{Cg} 2$ $\mathrm{mm}, I_{\text {coil }} 1000 \mathrm{~A}$ and $w 100 \mathrm{kHz}$.

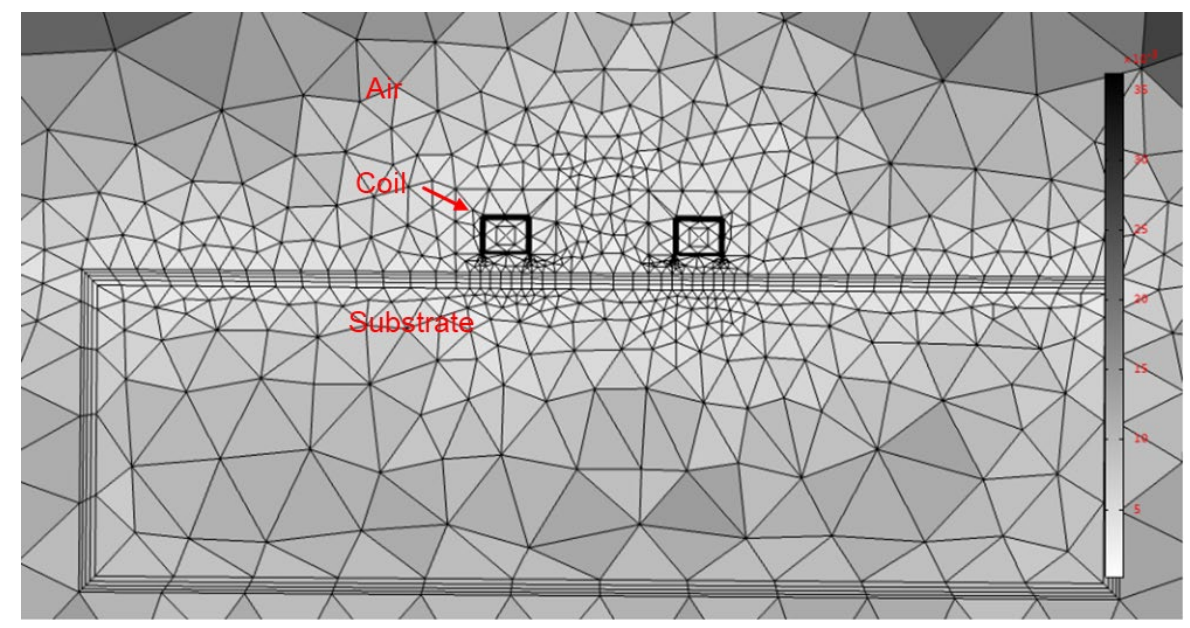

Figure 4: Finite element mesh distribution of the induction heating model.

Table 2: Parameters and variable values simulated in IH model to analyze heating temperature.

\begin{tabular}{lcl}
\hline Quantity & Symbol & Variable value \\
\hline Current flow on the coil [A] & $I_{\text {coil }}$ & $1000-2000$ \\
Frequency $[\mathrm{kHz}]$ & $\mathrm{W}$ & $50-150$ \\
Coupling gap $[\mathrm{mm}]$ & $\mathrm{Cg}$ & $2-4$ \\
& & \\
\hline
\end{tabular}

\section{Material and methods}

A stainless steel substrate $\mathrm{X} 3 \mathrm{CrNiMo13}-4$ with a dimension of $100 \times 30 \times 30 \mathrm{~mm}^{3}$ was used to analyze the induction heating induced by the coil on the substrate. Two copper inductors were employed in the experiment: N1, a single turn coil, and N2, a single turn coil equipped with MFC made of soft magnetic composition "ALPHAFORM MF." IH was carried out with a power generator type "Compact 20" from Plustherm Point AG with the maximum output power of $20 \mathrm{~kW}$. The inductor and the C-Box were clamped to the laser head and aligned coaxially with the DMD nozzle. The water line was connected to the heat station to be delivered to the 
inductor. A thermal imaging camera "Optris PIX" with temperature measuring ranges of 450$2000{ }^{\circ} \mathrm{C}$ and spectral ranges of $500 \mathrm{~nm}$ was employed to record the surface temperature of the substrate.

IH-DMD was carried out on a Trumpf TruLaser Cell 7020 CNC machine using a ytterbiumdoped yttrium aluminum garnet (Yb: YAG) disk laser with a wavelength of $1030 \mathrm{~nm}$, and a three-jet powder beam nozzles. Clad layers were deposited on the structural steel S235JRC+C substrate with a dimension of $25 \times 8 \times 100 \mathrm{~mm}^{3}$. Powder materials from stainless steel X3CrNiMo13-4 and Inconel ${ }^{\circledR} 625$ were examined. Samples were cross-sectioned to analyze the clad geometry and optical images were taken with a Keyence VHM 5000 Optical Microscope.

\subsection{Experimental setup}

The experimental tests were performed in two steps.

In the first step, induction heat treatment of the hybrid setup was studied to firstly determine the technical challenges and limitations of the integrated processes, and secondly, analyze the condition of the substrate heating. The experimental tests consider the induction heating temperature and its distribution on the surface of the substrate, examined with both inductors, and verifying the developed numerical simulation model of IH. In addition, the influence of the magnetic field on the ferromagnetic powder stream in a hybrid system was investigated.

The temperature measurement setup is shown in Figure 5. In this setup, the inductor was also mounted to the C-Box in the opposite direction shown in Figure 5-B, to provide access for the thermo-camera to detect the infrared radiation from the heated surface at the center of the coil Tc.

The induction power was varied in the range of $12-15 \mathrm{~kW}$ with the frequency of $75 \mathrm{kHz}$. The coupling gap of $2 \mathrm{~mm}$ is adjusted and $I_{\text {coil }}$ was read from the control panel of the generator. 
Accordingly, $I_{\text {coil }}$ was 1045 A and 820 A with inductor N.1 and N.2 respectively in the singleshot state when the power supply was set to $15 \mathrm{~kW}$. At $12 \mathrm{~kW}$ power generator, $I_{\text {coil }}$ at inductor N.1 was 946 A. These values were used in order to verify the simulation model of IH.
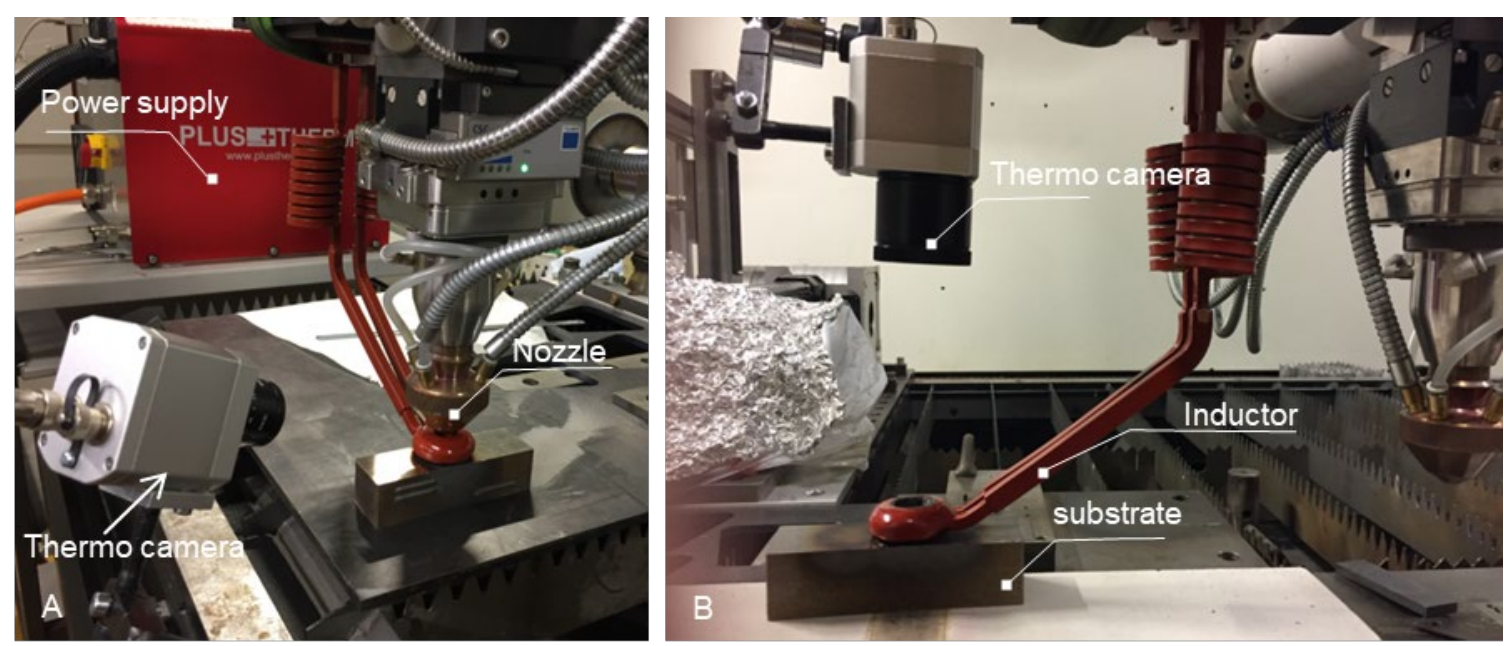

Figure 5: Temperature measurement setups: A, Temperature measurement under the coil (Te point); $\mathrm{B}$, Temperature measurement at the center of the turn (Tc point)

The influences of the magnetic field on the ferromagnetic powder were studied in two setups.

In the first setup, a conical tube with a small outlet of $2 \mathrm{~mm}$ filled with the stainless steel X3CrNiMo13-4 powder and positioned on the top of the coil. Powder could flow down linearly due to the gravity and pass through an induction coil. The maximum induction power with the frequency range of $70-140 \mathrm{kHz}$ was tested. In the second setup, IH-DMD configuration has been examined in which powder was delivered to the nozzle from the powder feeder, three lines of powder jet exited from the nozzle, and pass through the induction coil.

In the second step, the deposition of Inconel ${ }^{\circledR} 625$ powder on the $\mathrm{S} 235 \mathrm{JRC}+\mathrm{C}$ steel with $\mathrm{IH}-$ DMD setup was carried out using inductor N.2. Surface temperature at Tc: $650^{\circ} \mathrm{C}$ was measured according to the setup shown in Figure 5-B. The initial laser parameters for deposition of Inconel ${ }^{\circledR} 625$ were selected from the database, listed in Table 3. These parameters were considered as a reference parameter set. Due to the additional thermal load of the IH process to the DMD process, in the IH-DMD experiment, powder feed rates are increased stepwise by $20 \%$ from the reference value to analyze the maximum achievable deposition rate. The 
influence of the powder mass flow, feed rate, and spot size on the clad geometry were investigated to deposit defect-free layers. The deposition rate was calculated from the crosssection of the samples concerning the area of the deposited layer.

Table 3: Reference laser DMD parameter set for deposition of Inconel ${ }^{\circledR} 625$.

\begin{tabular}{|c|c|c|c|c|}
\hline $\begin{array}{c}\text { Scan speed } \\
{[\mathrm{mm} / \mathrm{min}]}\end{array}$ & $\begin{array}{c}\text { Powder feed } \\
\text { rate }[\mathrm{g} / \mathrm{min}]\end{array}$ & $\begin{array}{c}\text { Track } \\
\text { Overlap [\%] }\end{array}$ & $\begin{array}{c}\text { Laser power } \\
{[\mathrm{W}]}\end{array}$ & $\begin{array}{c}\text { Laser spot } \\
\text { diameter }[\mathrm{mm}]\end{array}$ \\
\hline 996 & 14.56 & 50 & 1200 & 2.5 \\
\hline
\end{tabular}

\section{Result and discussion}

\subsection{Induction heating temperature and distribution}

Figure 6 shows the simulation results for induction heating at different coupling gaps $\mathrm{Cg}$, frequencies w and current flows $I_{\text {coil }}$ in the single-shot setup. Figure 6-A shows that the closer the gap between the substrate and the coil, the more intense the heating. Decreasing the coupling gap from $4 \mathrm{~mm}$ to $2 \mathrm{~mm}$ increases the temperature by around $60 \%$ in the first 2 seconds of heating. It can be due to the spread out of the magnetic field over a longer length by increasing the coupling gap. Therefore, the minimum $\mathrm{Cg}$ causes higher current density on the substrate, resulting in higher efficiency of the IH. 

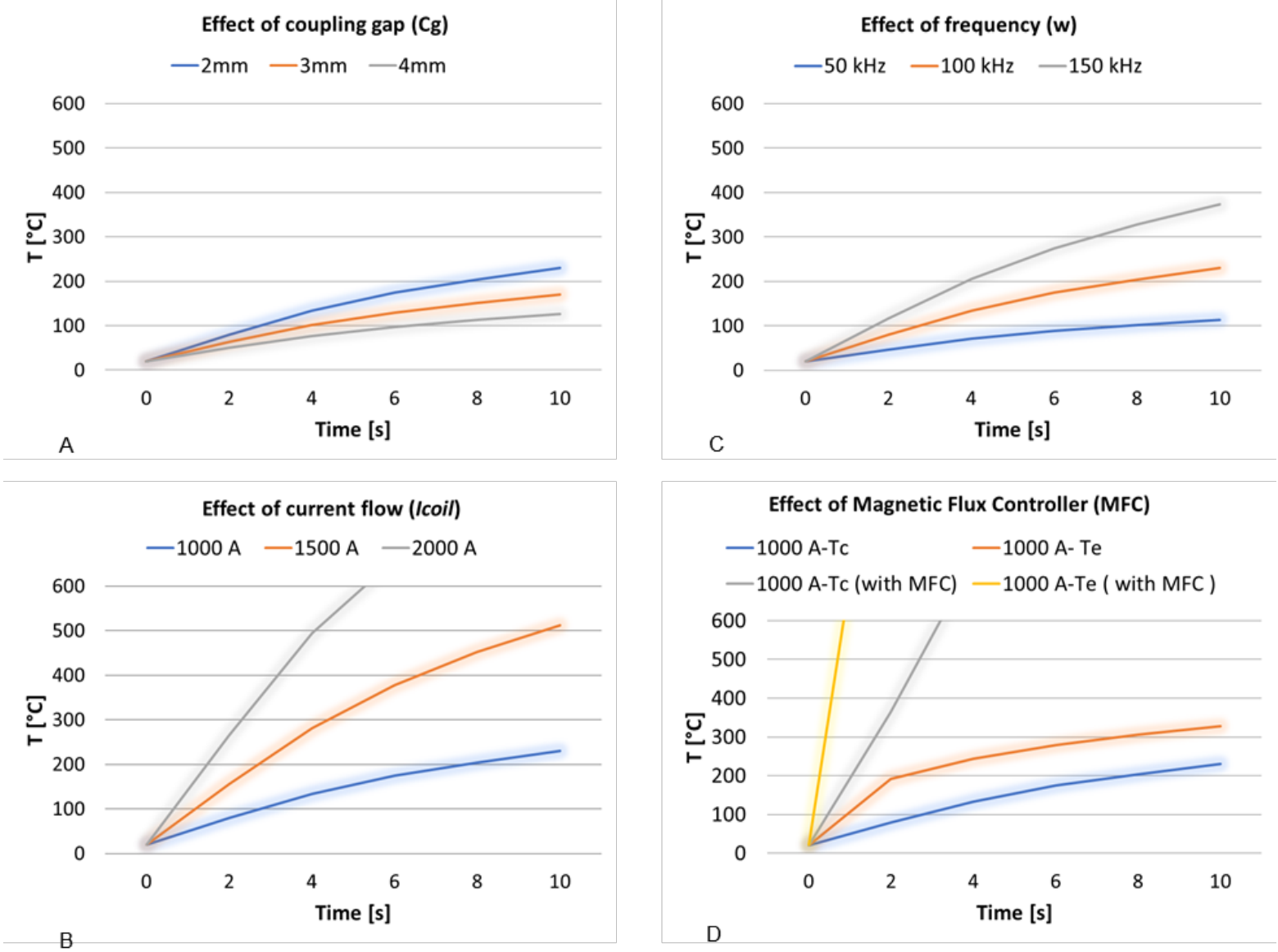

Figure 6: Simulation results of time-temperature at different IH parameters. A, coupling gap; B, electric current flow; $\mathrm{C}$, frequency; and $\mathrm{D}$, with and without applying magnetic flux controller MFC at Te and Tc point.

The correlation between the time-temperature and the frequency, as shown in the diagram 6-B illustrates that the frequency has a strong influence on the surface heating. By increasing the frequency from $50 \mathrm{kHz}$ to $150 \mathrm{kHz}$ the surface temperature increases by a factor of almost 2.5 during the first 2 seconds of the heating period, which indicates that less power is required to achieve a certain temperature on the substrate. Figure 6-C shows the significant role of the current flow on the heating temperature. By doubling the current from $1000 \mathrm{~A}$ to $2000 \mathrm{~A}$, the temperature increases approximately by the factor of four. This behavior can be explained by the mathematical relationship between power dissipation and electric current through a resistance followed the form of the equation (7).

$$
P=I^{2} R
$$


The calculated power dissipation on the substrate increase from $466 \mathrm{~W}$ to $1864 \mathrm{~W}$ in $1000 \mathrm{~A}$ and 2000 A respectively. Figure 6-D shows the temperature-time curves under the coil at Tc and Te points as well as the effect of MFC on the heating temperature. The Te and Tc series in the diagram illustrates that the heating temperature is higher under the face of the coil than in the center of the turn. The temperature gradients of these two points are approximately $100^{\circ} \mathrm{C} / \mathrm{s}$. It can also be seen in Figure 6-D a remarkable evolution in heating temperature induced by the coil with MFC. Simulation of the magnetic flux density B, induced by the coil on the substrate can explain this fact (cf. Figure 7). By applying MFC, the magnetic fields are concentrated under the coil rather than being widely distributed in the air zone, and reached the maximum value of $3.98 \mathrm{~T}$. Consequently, the power dissipation reaches to $2810 \mathrm{~W}$ at $1000 \mathrm{~A}$ after assigning of MFC to the simulation study, which is almost five times higher than the setup without MFC.

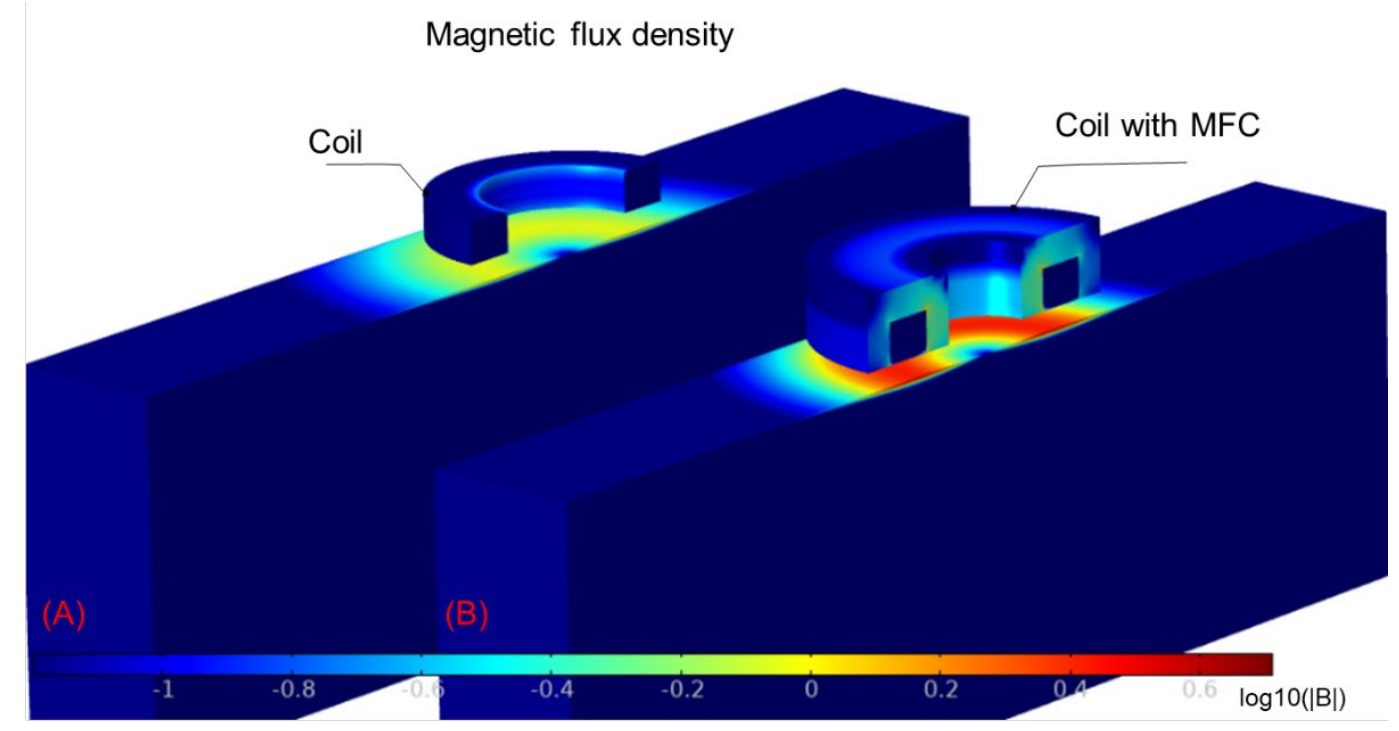

Figure 7: Magnetic flux density B induced on the substrate by (A), a normal coil; (B), a coil with MFC. Legend color shows the magnetic flux density of $\log 10(|\mathrm{~B}|)$, i.e., B ranges from 0.1 to 3.98 [T].

It can be concluded from Figure 6 and the discussion above that the smaller the coupling gap, the higher the frequency of the magnetic field, the higher the electric current in the coil and employing MFC, the more rapid the heating of the substrate. However, applying a small value of $\mathrm{Cg}$ in IH-DMD is limited by some factors. Firstly, the gap between the coil and a solid layer 
under the coil decreases oppose of the laser scanning direction due to the formation of a clad layer, as shown in Figure 2. The deposited layer may cause a risk of blockage of the inductor movement if the coated height exceeds the initial coupling gap. This factor alone can cause the vital need to design a protective circuitry to stop the IH-DMD process immediately if the deposited layer touches the inductor or travels too close to its vicinity. Secondly, the coated layer has a smaller Cg compared to the substrate surface, resulting in higher heating intensity on the coated layer relative to the substrate according to Figure 6-A. This fact may potentially lead to undesired heating of the fabricated layer. Finally, the DMD process contains spatter during the deposition of the powder, and thus, close distance to the harsh environment of the melt pool may decrease the life time of the coil.

Overall, applying MFC is the most efficient factor among the other parameters to reduce the heating time. Nevertheless, the concentration of the magnetic field under the face of the coil with MFC leads to a significant thermal gradient between Tc and Te points. For instance, temperatures at $\mathrm{Tc}$ and $\mathrm{Te}$ points reach to $365^{\circ} \mathrm{C}$ and $1283^{\circ} \mathrm{C}$, respectively, after two seconds of heating in a single shot state. In Figure 8 the results of an axisymmetric simulation of the temperature pattern induced by the coil with MFC, in a single-shot state, and after two seconds of heating is plotted, showing a ring-form heating pattern on the substrate surface. However, heating conditions in an IH-DMD is in a scanning state with the scans peed of the DMD process.

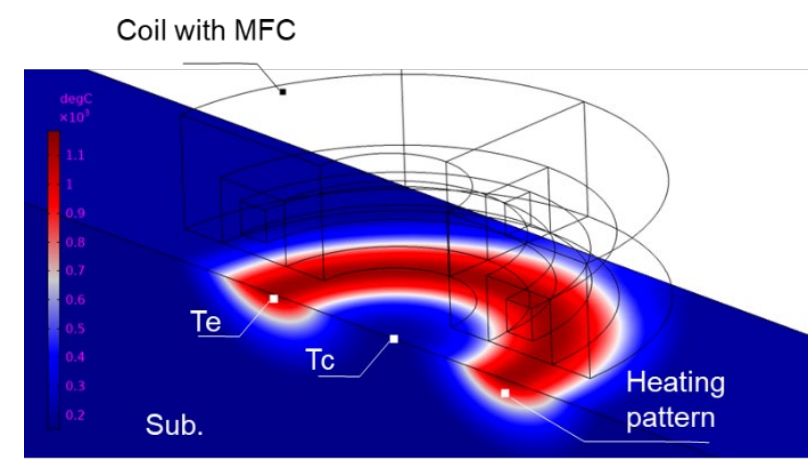

Figure 8: Simulation of the axisymmetric model of heat pattern on the substrate induced by the coil with MFC, $1000 \mathrm{~A}$, in two seconds, and in a single shot. 
In Figure 9 the simulation results of the heat distribution during scanning, and the curve of the temperature-time at the Tc point within five seconds of the scanning with a travel speed of 0.01 $\mathrm{m} / \mathrm{s}$ are plotted. The heating curve shows that the temperature at the center of turn Tc reached $546^{\circ} \mathrm{C}$ after 2 seconds of scanning and stay in steady condition over the length of the path. It can be expected from this simulation result that the MFC is the most effective way to be employed in IH-DMD setup and brings the advantage of uniformly preheating of the melt pool zone over the scanning length, which is an essential factor in the deposition process. However, careful design, as well as proper material selection of MFC, is necessary due to two reasons: firstly, the decision to apply MFC to the IH-DMD setup depends strongly on the available laser WD and shape of the coil, particularly the ID of the coil, because mounting this element requires additional space around the copper coil. Secondly, the high thermal loaded condition of laser process, which MFC should withstand in the long term. By reduction of the travel speed, the surface temperature can be leveled up, as the calculated surface temperature at Tc raised from $546^{\circ} \mathrm{C}$ to $613^{\circ} \mathrm{C}$ by a $20 \%$ decreasing of the scan speed.
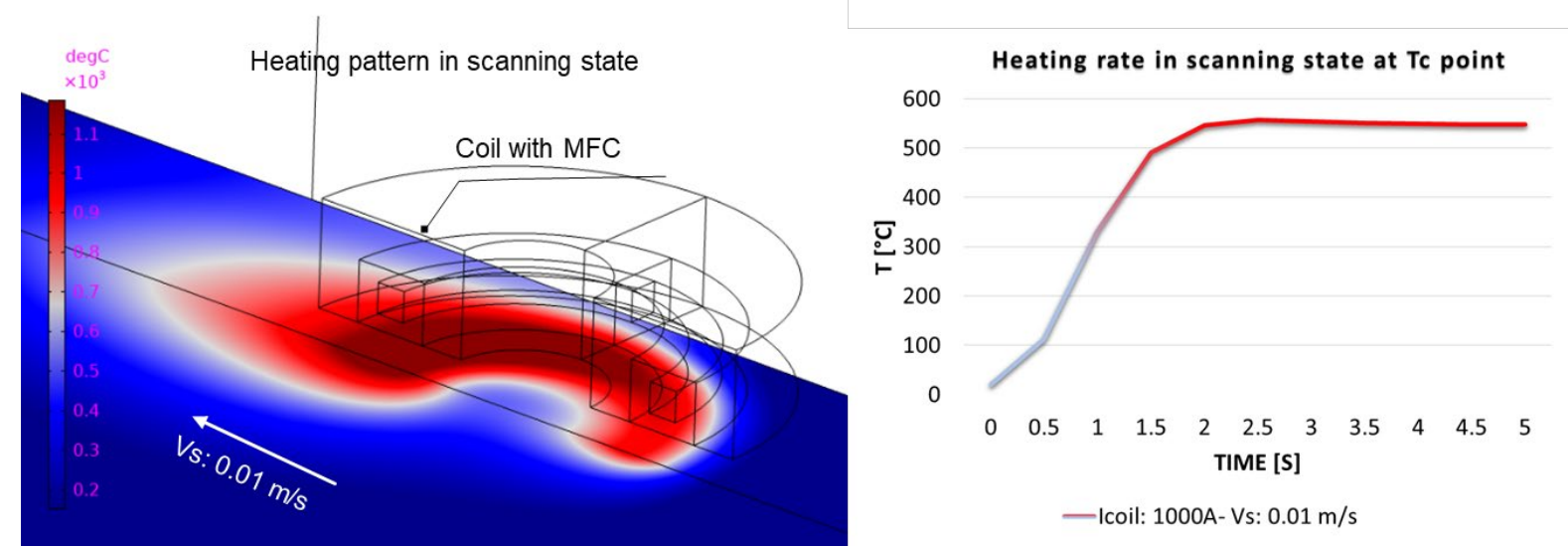

Figure 9: Induction heating of the substrate in the scanning state, $1000 \mathrm{~A}$, with $\mathrm{MFC}, \mathrm{Vs}=0.01 \mathrm{~m} / \mathrm{s}$ : Left, heating pattern during moving of the substrate; Right, time-temperature curve achieved on the substrate at the center of turn Tc.

Figure 9-B shows that IH takes a certain time (in this case, two seconds) to rise to the maximum temperature and becomes linearly stable. This heating condition may have a negative impact on the clad quality at the beginning of the deposition path when the temperature is still in the 
evolution cycle. A practical solution to address this concern can be via deposition strategy, in which $\mathrm{IH}$ is turned on with an additional distance from the target point of the DMD process. For implementing the proposed solution strategy, a starting distance can be chosen in a CAM software by the function called "Lead-in." This strategy can compensate for the heating time delay from the starting point and can diminish the risk of inhomogeneous heating at the starting point of IH-DMD process. The lead-in distance depends on the size of the coil and the scan speed.

In order to validate the numerical simulation model, the experiment was conducted in a singleshot state. Table 4 compares the IH results of the simulation and the experiment using inductor N.1 in which the heating time has been recorded at the point Te when the temperature reached to $500^{\circ} \mathrm{C}$. The heating time at $946 \mathrm{~A}$ in the experiment and simulation are 29 and 42 seconds, respectively. The same trend can be seen in the results examined with $1046 \mathrm{~A}$, which indicates that the developed IH simulation model can estimate the heating temperature with coefficient accuracy of around $70 \%$. This deviation can be due to the simplification of the model (e.g., neglecting hysteresis loss). Figure 10 compares the simulation and experiment curve of the heating temperature at Te and Tc points with inductor N.2. The power supply was turned off after 12 seconds (shown by the "off" symbol in the graph), and then the temperature value was recorded when part cooled down.

Table 4: Comparison of heating temperature in the simulation model (Sim.) and experiment (Exp.), examined by the inductor N.1 (normal coil), and measured at Te: $500^{\circ} \mathrm{C}$ in single-shot IH.

\begin{tabular}{cccc}
\hline \multicolumn{4}{c}{ Inductor N.1 } \\
\hline $\begin{array}{c}\text { Power } \\
{[\mathrm{kW}]}\end{array}$ & $\begin{array}{r}I_{\text {coil }} \\
{[\mathrm{A}]}\end{array}$ & $\begin{array}{c}\text { Heating time (Exp.) } \\
{[\mathrm{s}]}\end{array}$ & $\begin{array}{c}\text { Heating time (Sim.) } \\
{[\mathrm{s}]}\end{array}$ \\
\hline 12 & 946 & 29 & 42 \\
15 & 1046 & 16 & 23 \\
& & & \\
\hline
\end{tabular}

A similar deviation was observed between simulation and experimental results with inductors N.2 up to $500^{\circ} \mathrm{C}$ at the Te point. Despite the model simplifications, the agreement between 
experiment and simulation is good above $600^{\circ} \mathrm{C}$ at the Te point, and temperature-time curves of "Sim" and "Exp" are close. This fact can prove the role of hysteresis heating and temperature dependence of magnetic permeability of the material, in which the material of the substrate loses its magnetic properties gradually. Above $600^{\circ} \mathrm{C}$ (Curie temperature), attribution of hysteresis heating is irrelevant. The simulation result of the heating curve at the Tc point agrees with the experiment, as the temperature evolution in this point is mainly governed by conducted heat from the Te point.

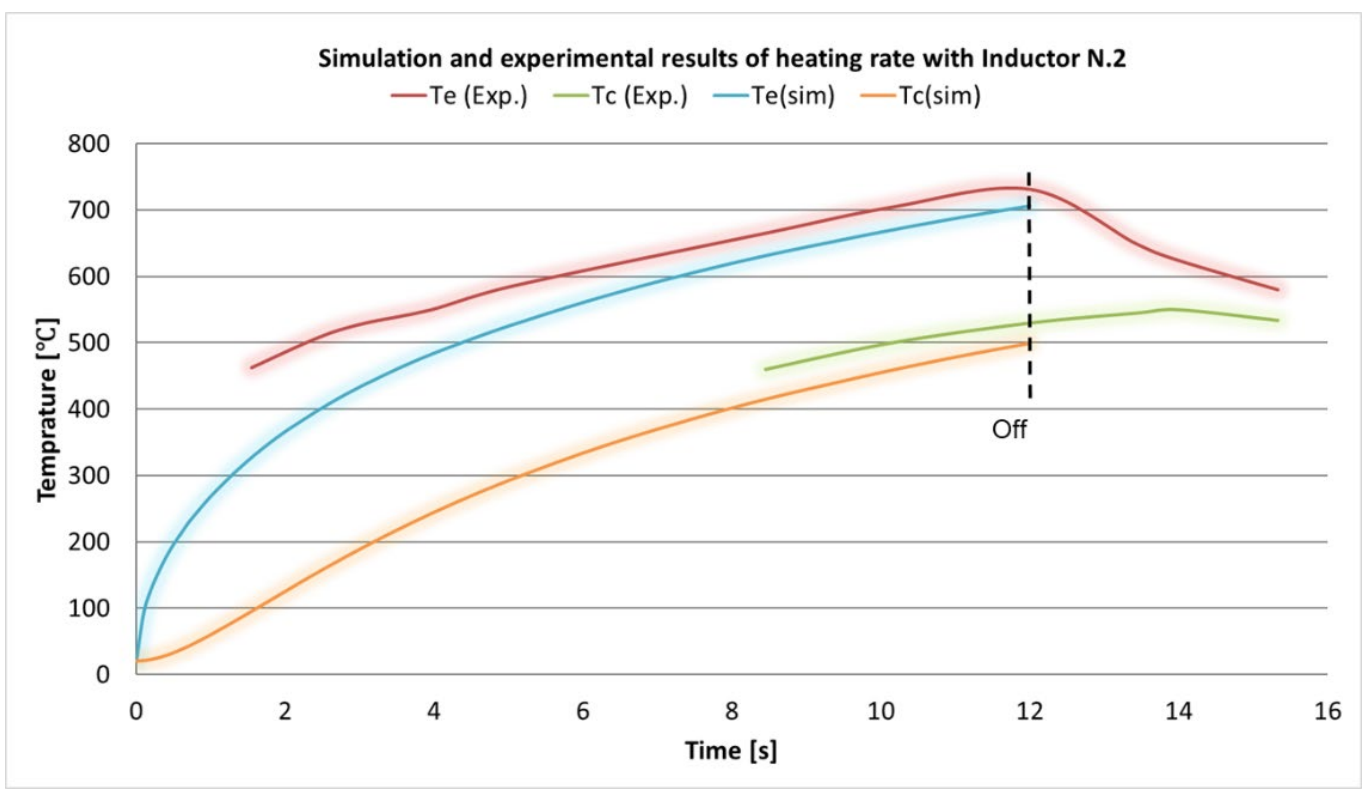

Figure 10: Comparison of the heating temperature in the simulation and experiment examined by the inductor N.2 (coil with MFC), $\boldsymbol{I}_{\text {coil }} 820 \mathrm{~A}$, in single-shot IH

\subsection{Technical challenges and limitations}

During the experimental test, a non-steady coupling gap condition was observed while heating the part in a single-shot state. When the induction power generator was turned on to heat up the part, the head of the coil was at first pulled down toward the substrate and then pushed back when the substrate became hot, as shown by the arrow in Figure 11. This was due to the force that can occur in interaction of the magnetic field generated by the coil with an external magnetic field generated by a substrate called "electrodynamic force [23]". This result specifies the necessity of robust design of the inductor to tolerate the electrodynamic force loaded on the inductor and to maintain the coupling gap constant. 


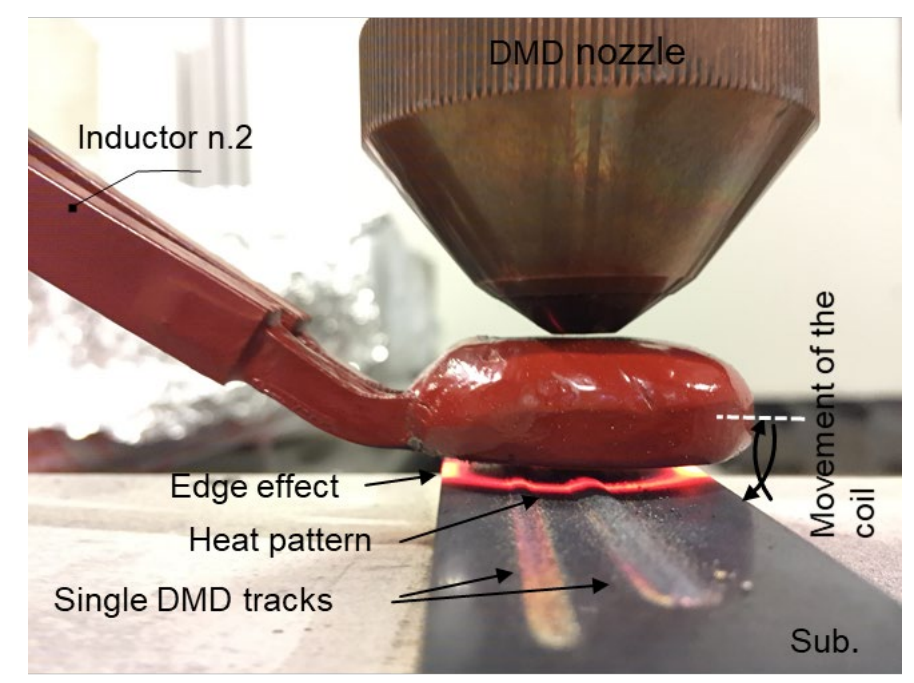

Figure 11: IH-DMD process presenting the ring form heat pattern under the coil and the edge effect phenomena on the edges of the substrate. Coil movement (pushed down and pulled back) due to the electrodynamic force shown by the arrows.

Figure 11 also illustrates that the heating rate is higher at the point of the sharp dimension changes of the substrate, which is called the "edge effect [12]". The edge effect can be expected during IH-DMD of a flat rectangular-shaped substrate, which is relatively smaller compared to the size of the coil. However, the edge effect was not notable on the DMD coated layer due to the round edge of the clad as realized by the heat pattern on the solidified track shown in Figure 11.

In IH-DMD, a layer can be deposited on a thin or thick layer underneath. Thinner layers correspond to a smaller mass of metal, which can be heated to higher temperatures than thicker areas. This fact, plus the edge effect during IH-DMD process, presents the difficulty in obtaining heat uniformly with constant IH parameters set. Therefore, real-time IH temperature feedback control is essential to achieve local temperature uniformities over the length of layer deposition.

The experimental result of the influence of magnetic field on powder stream of ferromagnetic stainless steel X3CrNiMo13-4 presented a visual outward deviation of powder flow when passing through the induction coil in the first setup. Changing the frequency of the power supply did not have any notable effect on the deviation angle. Despite the first setup observation, in 
IH-DMD setup, no visual deviation, fluctuation of powder stream or attraction of powder to the inner side of the coil were observed. The different behavior of powder flow in these two different setups can be due to the velocity of powder particles in the DMD process, which provides enough inertia for the powder particles to escape a magnetic field of induction coils.

Although the examined ferromagnetic powder materials could pass through the electromagnetic field of the coil and delivered to the processing zone, in the next step, when the nozzle was positioned above the substrate to start IH-DMD process, powder particles were reflected from the substrate and trapped in the magnetic field. Attracted powder particles aligned under the face of the coil and formed into vertical chains. This created a conductive bridge between the coil and the substrate, causing a short circuit in which the electric current can pass through the particle chains, resulting in burning and explosion of powder chains, as shown in Figure 12. This event occurred fewer times in deposition of layers by IH-DMD, since most of the powders were inserted into the melt pool, delaying the described problem.

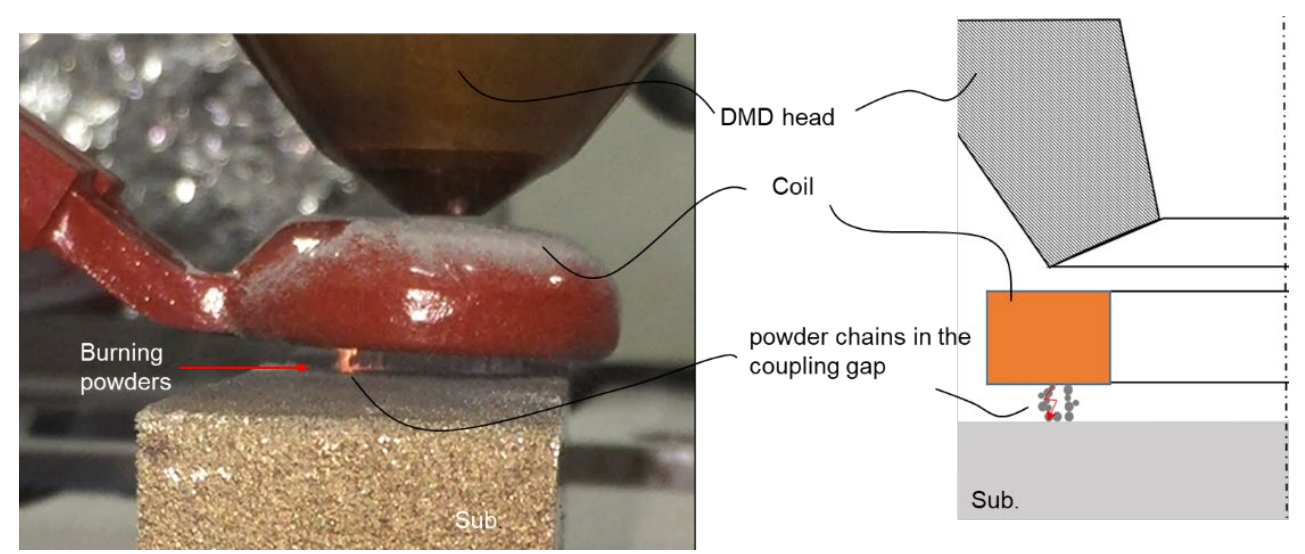

Figure 12: Forming powder chains in the coupling gap during IH-DMD setup due to the electromagnetic field, causing a short circuit between the coil and the substrate, resulting in the burning or explosion of powders.

The other fact observed during the experiment with $\mathrm{X} 3 \mathrm{CrNiMo13-4}$ stainless steel powder is that the accumulated powders under the face of the coil were oxidized and polluted during the IH-DMD process. This condition was visually realized from the color of the powder, which changed to dark brown. By turning the power generator off, these powders were unloaded from 
the coil. Consequently, these polluted powders may contaminate the surface, which will be coated in the next deposition sequences.

It can be concluded from the discussion above that processing of ferromagnetic powder X3CrNiMo13, with an IH-DMD setup faces technical challenges and needs additional handling and inductor specification compared to the processing of paramagnetic powders. The solutions that can be examined to address these technical challenges may possess the following properties: Firstly, the bottom side of the inductor coil is isolated with a non-electrical conductive layer to prevent a short circuit and the flow of the electric current through the powder particle chains. This shielding layer should be thin due to the limited WD space and role of $\mathrm{Cg}$ factor on the heating efficiency and resist in a high thermal load during the laser process. Secondly, an additional sequence needs to be considered while programming DMD paths to unload the accumulated powder under the face of the coil to a non-processing zone to prevent the risk of metallurgical contamination of the deposited layers.

\subsection{Clad geometry and deposition rate}

Figure $13 \& 14$ shows the optical image of the cross-sectioned single tracks as well as the experimental results of build-up rate and melt pool depth with DMD and IH-DMD setups. The results of the sample, deposited with reference DMD parameters set, are shown in Figure 13-B and with the "R" symbol in the chart. The deposition curve of the DMD process shows an increase in deposition rate by raising the powder feed rate from 14.56 to 20.38 [g/min]. However, the melt pool depth decreases accordingly, and there is not sufficient metallurgical bonding between the clad layer and the substrate in the powder feed rate above $40 \%$ from the reference parameter. 

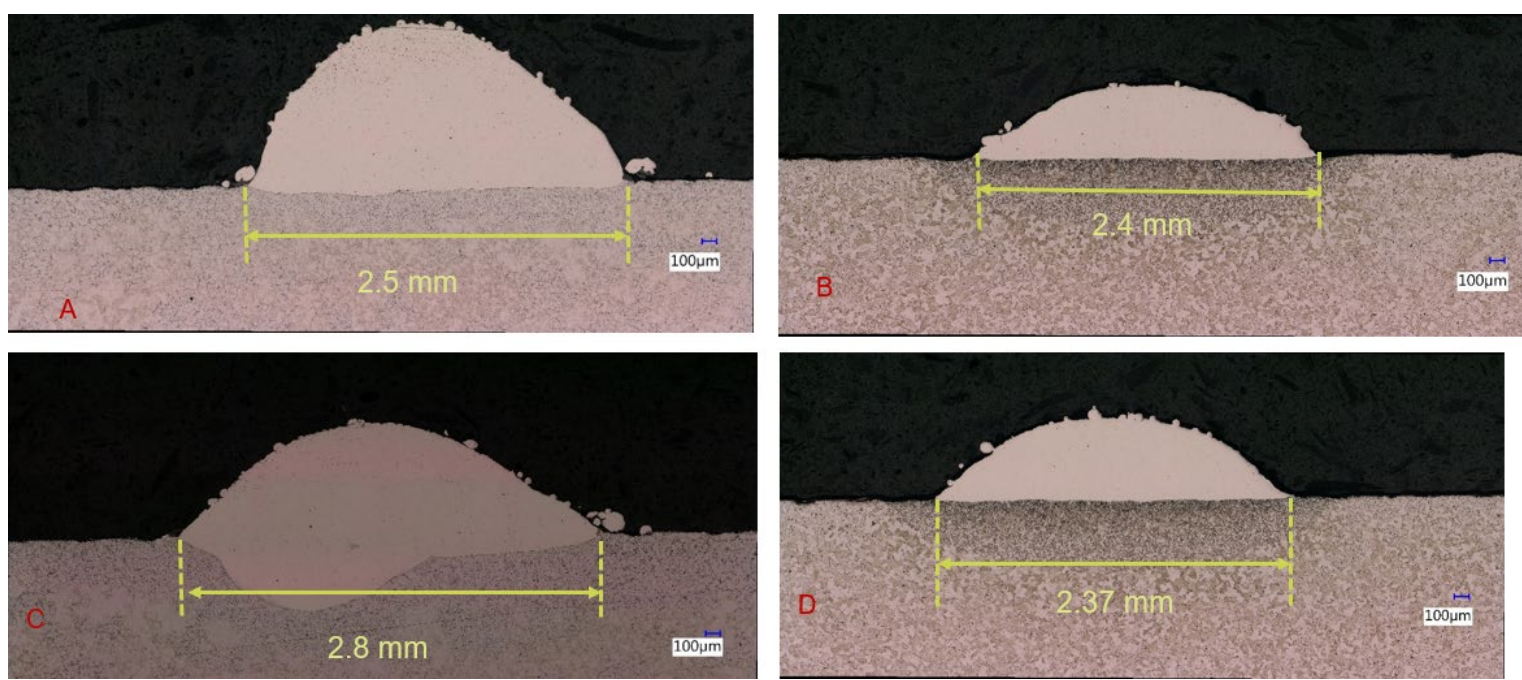

Figure 13: Cross section of single track deposited, A: with IH-DMD at $29.12 \mathrm{~g} / \mathrm{min}, \mathrm{B}$ : with DMD at $14.56 \mathrm{~g} / \mathrm{min}$ (reference parameter set), C: with IH-DMD at $20.38 \mathrm{~g} / \mathrm{min}$, D: with DMD at $20.38 \mathrm{~g} / \mathrm{min}$. The surface temperature of the substrate in IH-DMD is $650^{\circ} \mathrm{C}$.

By applying IH-DMD setup, melt pool depth increases from 0.03 to $0.5 \mathrm{~mm}$ at a powder feed rate of 20.38 [g/min]. The higher melt pool depth allowed applying a higher powder feed rate up to $120 \%$. Accordingly, the deposition rate increased 3.6 times without a lack of fusion.

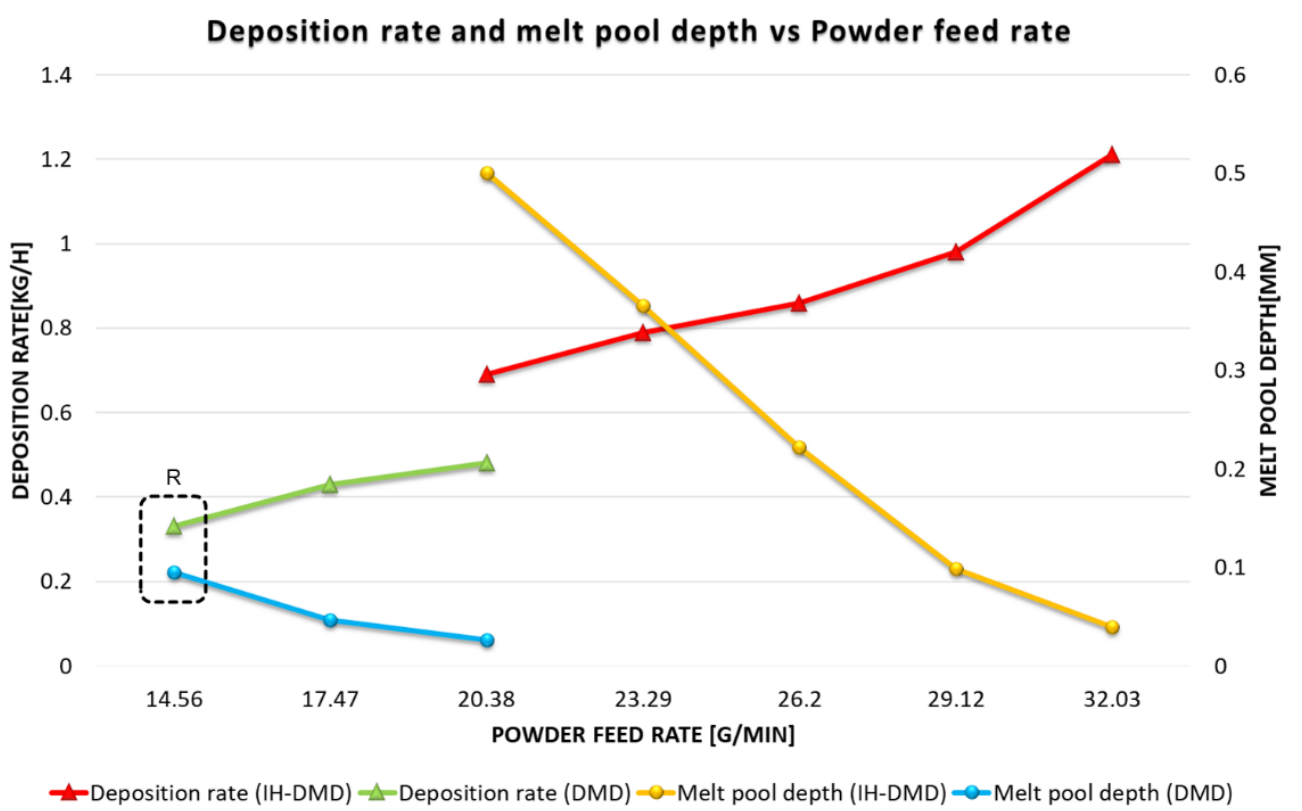

Figure 14: Deposition rate and melt pool depth of single track in different powder feed rate in DMD and HI-DMD. Powder material and substrate are Inconel 625 and the structure steel S235, respectively.

The higher melt pool depth in IH-DMD can be due to the additional heat generated by the IH into the melt pool, and the reduction of heat losses to the surrounding of the melt pool (or the 
effect of one of them). However, to explain the mechanism behind this result precisely, a combined model of DMD and IH needs to be developed to analyze the surface temperature and the cross-section of the melt pool.

It also can be seen from Figure 14 that the deposition rate leveled up from the value of 0.48 $\mathrm{kg} / \mathrm{h}$ in DMD to $0.69 \mathrm{~kg} / \mathrm{h}$ in IH-DMD curves at a steady powder feed rate of $20.38 \mathrm{~g} / \mathrm{min}$. This result can be explained in comparison with the clad geometry of samples. Clad produced with IH-DMD is thicker and wider compared to the DMD process at the same powder feed rate (cf. Figure $13 \mathrm{C} \& D)$, which represents the size of its melt pool before solidification. The size of the melt pool increases with increasing temperatures in IH-DMD, resulting in more efficient powder catchment, and consequently, a higher powder melting efficiency and deposition rate.

Figure 13-A shows the cross section of a single track produced with IH-DMD at the powder feed rate of $29.12 \mathrm{~g} / \mathrm{min}$ (named as sample N.1 In the following discussion). The deposition rate is $0.99 \mathrm{~kg} / \mathrm{h}$, which is three times higher than the reference sample, but the penetration depth is the same value of $0.1 \mathrm{~mm}$, and the clad layer is much thicker. Consequently, the ratio between clad width and clad height called Aspect Ratio (AR) is 2.7, which is about two times lower than the AR value of 5.9 in the reference sample. Two approaches were examined to increase the AR, namely larger spot size and higher scanning speed. Single tracks were deposited with these approaches (sample N.2 and N.3). Table 5 summarizes the parameters, and experiment result of deposition rate, melt pool depth, AR. In sample N.2, powder mass flow decreases $10 \%$, and spot size increases accordingly. A preheated surface in IH-DMD allows for a selection of higher spot size of $2.9 \mathrm{~mm}$, which leads to a wider melt pool width and, as a result, increases AR to 4.5 in the experiment. In sample N.2, the scanning speed increased by $40 \%$, resulting in a thinner clad due to less powder deposited per unit length. The second approach provides a higher AR of 5.1, but the deposition rate decreases to $0.75 \mathrm{~kg} / \mathrm{h}$, approximately $24 \%$ lower than the first approach. 
Table 5: Laser process parameters in IH-DMD. In N.1, laser parameters of reference sample were selected but with a higher powder feed rate of $29.12 \mathrm{~g} / \mathrm{min}$. In N.2 and N.3 spot size and scan speed was tuned to achieve higher AR.

\begin{tabular}{ccccccc}
\hline Sample & $\begin{array}{c}\text { Power } \\
\text { feed rate } \\
{[\mathrm{g} / \mathrm{min}]}\end{array}$ & $\begin{array}{c}\text { Spot } \\
\text { size } \\
{[\mathrm{mm}]}\end{array}$ & $\begin{array}{c}\text { Scanning } \\
\text { speed } \\
{[\mathrm{mm} / \mathrm{min}]}\end{array}$ & $\begin{array}{c}\text { Deposition } \\
\text { rate[kg/h] }\end{array}$ & $\begin{array}{c}\text { Penetration } \\
\text { depth[mm] }\end{array}$ & $\begin{array}{c}\text { Aspect } \\
\text { ratio }\end{array}$ \\
\hline N.1 & 29.12 & 2.5 & 996 & 0.99 & 0.1 & 2.7 \\
N.2 & 26.2 & 2.9 & 996 & 0.83 & 0.13 & 4.5 \\
N.3 & 26.2 & 2.5 & 1394 & 0.75 & 0.2 & 5.1 \\
\hline
\end{tabular}

In order to evaluate the metallurgical bonding of layers fabricated by these clad geometry, multiple tracks with 50\% overlap were deposited with IH-DMD setup. Figure 15-A shows the cross-sectioned image of a single-track and of multiple layers sample N.1 in which bonding errors were observed at the clad interface of multi-tracks. However, porosities disappeared in sample N.2 and N.3. This result indicates that a low AR and high contact angle tend to cause lack of fusion between overlapping clad tracks, presenting the necessity of re-characterization of laser DMD process parameters in IH-DMD when higher powder feed rate is applied to achieve defect-free layers.
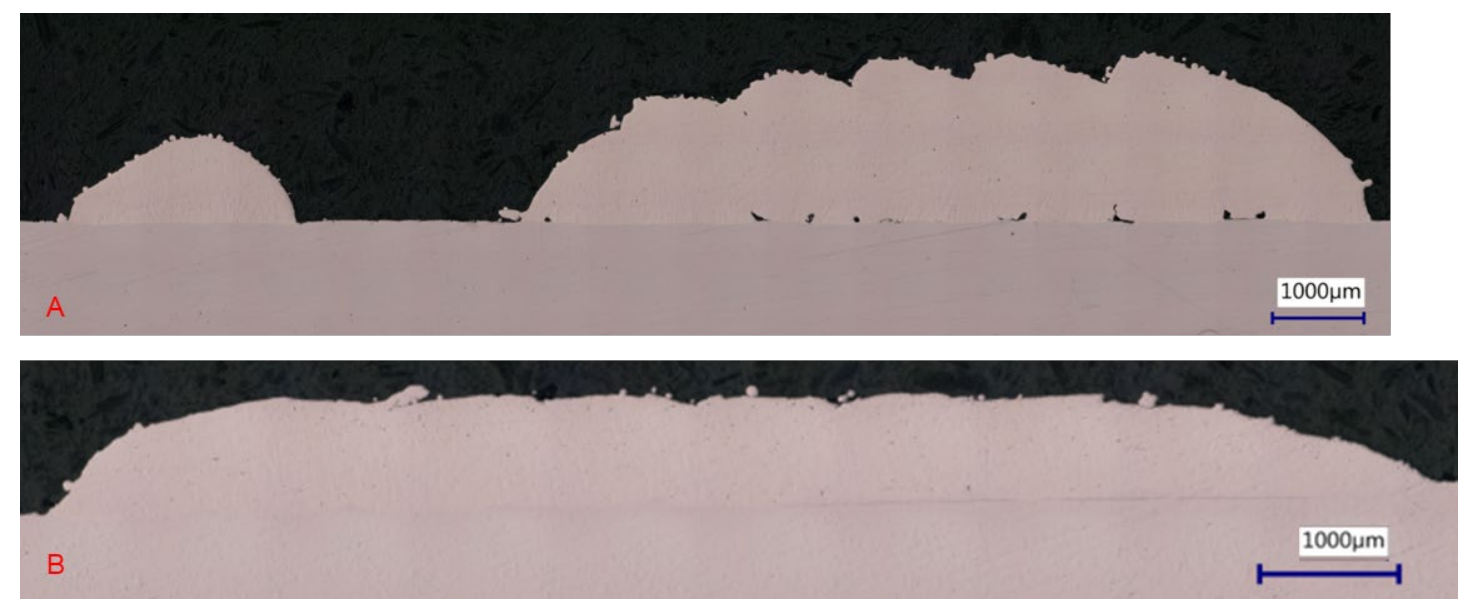

Figure 15: Cross section image of samples deposited from Inconel 625 powder material on the structure steel S235 with IH-DMD: A, sample N.1; B, sample N.3

\section{Conclusions}


The roles of DMD and IH specifications on a hybrid process, including working distance, coupling gap, current density, frequency, and magnetic flux controller (MFC), have been discussed, and technical challenges have been addressed. A finite element simulation model was developed and validated with the experiment, enabling a prediction of the requirement of IH parameters for DMD application, which mostly assisted the setup design and process optimization and reduced the number of experimental investigations. Layers were deposited with an IH-DMD setup, and the productivity rate and clad geometry of the deposited tracks were examined. Based on the results of the deposited layer, the laser parameters were tuned to increase the aspect ratio, and a layer without bonding error was deposited with the IH-DMD setup.

The following key findings were achieved:

- The simulation results show that a lower coupling gap, higher frequency, higher electric current flow in the coil, and applying the MFC result in a rapid heat up of the surface of the substrate. The minimum possible coupling gap can be adjusted, considering the thickness of the coating layer. Protective circuitry is vital to stop the process in uneven contact between the coil and the deposited layer.

- Although a ringed heating pattern was formed under the coil by using MFC, it was the most effective way to employ MFC in the IH-DMD setup from a rapid heating perspective. However, applying MFC to the IH-DMD setup depends strongly on the available space of laser WD, shape of the coil as well as its resistance to the high temperature environment of the DMD process.

- Processing of ferromagnetic powder X3CrNiMo13 with the IH-DMD was challenging due to the effect of a magnetic field on powder particles during the coating process. The accumulated powder disrupted the DMD process in various ways, including a short circuit event, burning, and oxidation of powder, which destabilized the DMD process. 
- The IH-DMD allowed a higher deposition rate than DMD due to the temperature field generated by induction, allowed inserting more powder material to the melt pool. Accordingly, the deposition rate could be increased by a factor of three in a single track.

- Increasing the powder feed rate resulted in a higher clad height and lower AR, causing bonding errors in multiple layers. Therefore, two approaches, including increasing the spot size and scan speed were examined to enhance the situation and resulted in an improvement of the AR from 2.7 to 4.5 and 5.1, respectively.

\section{Acknowledgements}

This work was financially sponsored by the Swiss innovation agency Innosuisse [Grant number 27436.1 PFNM-NM], which is gratefully acknowledged. The authors would like to sincerely acknowledge Mr. Matthias Brunner from Plustherm Point AG for his technical consulting and Mr. Sven Friedel from COMSOL AG. for his support in IH simulation, Mr. Jordan Borinelli for preparing the required metallography cross-sections during his internship period at ETH, Mr. Sacha Schob From MAN Diesel \& Turbo and Mr. Alexander Barth from Oerlikon Metco for materials supplying.

\section{References}

[1] Strickland, J. D. (2016). Applications of Additive Manufacturing in the marine industry. Proceedings of PRADS2016 4: p. 8th.

[2] Rayna, T. and Striukova, L. (2016). From rapid prototyping to home fabrication: How 3D printing is changing business model innovation. Technological Forecasting and Social Change 102: p. 214-224 DOI: https://doi.org/10.1016/j.techfore.2015.07.023.

[3] Haimbaugh, R. E. (2001). Practical induction heat treating. ASM international.

[4] Baake, E. and Nacke, B. (2016). Induction Heating: Heating / Hardening / Annealing / Brazing / Welding. Vulkan Verlag.

[5] Rudnev, V., Loveless, D., Cook, R. L., and Black, M. (2016). Handbook of Induction Heating, Second Edition. Taylor \& Francis.

[6] Zhou, S., Huang, Y., Zeng, X., and Hu, Q. (2008). Microstructure characteristics of Nibased WC composite coatings by laser induction hybrid rapid cladding. Materials 
Science and Engineering: A 480(1): p. 564-572 DOI:

https://doi.org/10.1016/i.msea.2007.07.058.

[7] Jonnalagadda, A., Scharek, S., Bratt, C., Albert, D., and Weitzer, T. (2011). Induction assisted laser cladding for high deposition rates. in International Congress on Applications of Lasers \& Electro-Optics. LIA.

[8] Nowotny, S., Brueckner, F., Thieme, S., Leyens, C., and Beyer, E. (2015). Highperformance laser cladding with combined energy sources. Journal of Laser Applications 27(S1): p. S17001 DOI: 10.2351/1.4817455.

[9] Wang, D., Hu, Q., Zheng, Y., Xie, Y., and Zeng, X. (2016). Study on deposition rate and laser energy efficiency of Laser-Induction Hybrid Cladding. Optics \& Laser Technology 77: p. 16-22 DOI: https://doi.org/10.1016/j.optlastec.2015.08.019.

[10] Dutta, B. (2015). Method of high rate direct material deposition. 2015, DM3D Tech LLC.

[11] Zinn, S. and Semiatin, S. (1988). Coil design and fabrication: basic design and modifications. Heat treating 12(3): p. 32-36.

[12] Rudnev, V., R Akers, R., Baake, E., Lynn Ferguson, B., Fasm, A Fett, G., Hoppe, R., Matlock, D., Nacke, B., Leibniz, Nash, P., Pfaffmann, G., Sisson, R., Vantyne, C., Zinn, S., Marken, K., D Henry, S., Kubel, E., Marquard, E., and Totten, G. (2014). ASM Handbook Volume 4C: Induction Heating and Heat Treatment.

[13] Toyserkani, E., Khajepour, A., and Corbin, S. F. (2004). Laser Cladding. CRC Press.

[14] Guo, W. (2007). Compact coaxial nozzle for laser cladding. 2007, Google Patents.

[15] Pinkerton, A. J. (2010). 16 - Laser direct metal deposition: theory and applications in manufacturing and maintenance, in Advances in Laser Materials Processing, J. Lawrence, J. Pou, D.K.Y. Low, and E. Toyserkani, Editors. Woodhead Publishing. p. 461-491.

[16] Yakey, C., Nemkov, V., Goldstein, R., and Jackowski, J. (2015). Best Practice for Design and Manufacturing of Heat Treating Inductors.

[17] Rob Goldstein, W. S., Micah Black (2014). Design and Fabrication of Inductors for Induction Heat Treating. ASM Handbook, Volume 4C, Induction Heating and Heat Treatment.

[18] Rudnev, V. and Totten, G. (2014). Magnetic Flux Controllers in Induction Heating and Melting.

[19] COMSOL (2019). AC/DC Module User's Guide, version 5.4", COMSOL, Inc, www.comsol.com. 2019.

[20] Kennedy, M. W., Akhtar, S., Bakken, J. A., and Aune, R. E. (2011). Analytical and Experimental Validation of Electromagnetic Simulations Using $\mathrm{COMSOL}^{\circledR}$, re Inductance, Induction Heating and Magnetic Fields. in COMSOL Users Conference, Stuttgart Germany. 
[21] Ho, C. Y. and Chu, T. (1977). Electrical resistivity and thermal conductivity of nine selected AISI stainless steels. 1977, thermophysical and electronic properties information analysis center

[22] GmbH, M. (2019). 1.4313 / AISI 415ia a chromium-nickel stainless steel. 2019.

[23] Rudnev, V. (2005). Electromagnetic forces in induction heating. Vol. 5. 